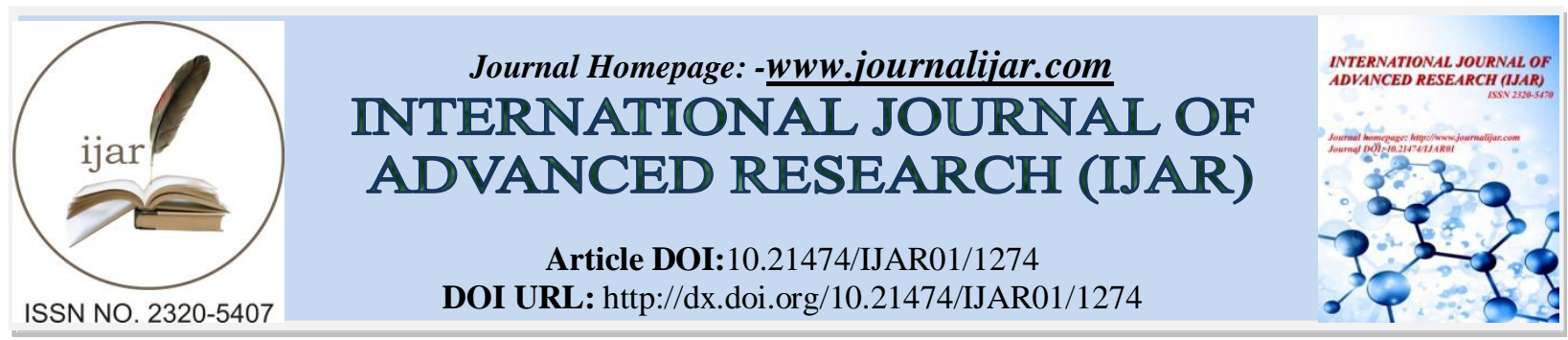

RESEARCH ARTICLE

\title{
DIVERSITY AND ABUNDANCE OF WATERBIRDS IN MAEKEL ZONE, ERITREA, NORTH EAST AFRICA.
}

RussomTeklay $^{1}$ and Kunduru Surender Reddy ${ }^{1}$. .

1. Department of Biology, Eritrea Institute of Technology, Mai Nefhi, Asmara, Eritrea, North East Africa.

2. Department of Zoology, C V Raman P G College (Kakatiya University), Mancherial, Telangana, India.

\section{Manuscript Info}

Manuscript History

Received: 12 June 2016

Final Accepted: 19 July 2016

Published: August 2016

Key words:-

waterbirds, Maekel zone, waterbirds, biodiversity, Egyptian Goose

\section{Abstract}

Permanent water bodies as well as naturally and artificially made wetlands are important for wildlife, because they provide a large variety of both food and breeding sites and improves survival during the non-breeding season. There is also a growing insight that even the smallest dams could be important, particularly for smaller species such as birds. Moreover, access to wetlands on the route to wintering or breeding areas is crucial that the migrants require a continuous input of energy during the, sometimes, very long journey. Such networks of wetlands are, in particular, important for birds because they perform long distance migrations. It is, therefore, not surprising that a priority of the international conservation agenda is to increase the protection of water bodies and wetlands. Eritrea is geographically very important as a migration route and stop-over location for many species of Palearctic migrants, including waterbirds. The study was carried out in Maekel Zone from November 2013 to March 2014, with the primary objective to evaluate species composition, relative abundance and distribution of waterbirds. Nine sites (dams) were selected for this study based on water holding capacity, vegetation complexity and previous birding history. Whole area search technique was employed through ground count. A total of 38 waterbird species were identified. The difference in species composition of birds among sites was significant. Sembel dam had the highest species diversity and evenness although the total count was low. Mai-Serwa dam, on the other hand, hosts few species only, but in dominant number. It has been noticed that bird's diversity and relative abundance was strongly influenced by the topography and productivity of the dams. Moreover, an important difference between the habitats in food production and the overall capacity to support necessary ecological needs is another factor. Although the relative abundance score of species was variable, the input that water birds are getting from the water bodies, in combination to surrounding irrigated farmlands, is undeniable. Unlimited human actions, sedimentation and pollution are the main threats to the survival of birds. For complete waterbird checklist of the region a comprehensive survey was conducted by using more precise mechanisms to measure bird's diversity in the region. 
Copy Right, IJAR, 2013,. All rights reserved.

\section{Introduction:-}

Mankind has been fascinated by birds, has observed, used, painted, wrote and sung, kept in captivity, protected and gave them a great respect, since the earliest times (Coltherd,1966). Birds can also be used as indicators of sites of high biodiversity. Bibbyet al. (1992) examined the available data for other groups of organisms to compare with bird, and showed that endemism, at least among large vertebrates, is often related to that of birds. In addition to research-based projects, these methods are gaining widespread use among agencies and extension groups to measure baseline patterns of diversity and gauge the effectiveness of management practices (Rosenstocket al., 2002). The presence of rare or endangered species, concentration of species, affiliations of certain species with important ecosystems at a site, and other bird complement have shown parallel significance for other biodiversity (WCMC, 1992). However, species richness alone can be a misleading measure of biodiversity, since resistance to disturbances, primary productivity, and adequate functioning of an ecosystem depend not only on the number of species, but also on other factors, including species abundance, and their levels of interactions from time to time (Magurran, 1998; Cardinaleet al., 2000; Tilman, 2000).

The value of birds to human society is, at present, widely recognized and can be extensively traced beyond their immediate products. Wildlife tourism, ranching and sustainable utilization of natural resources are promoted as a source of foreign exchange for developing countries. In many developed countries, the revenue from bird watching and related "industries" can be counted in millions of dollars. However, many advantages of birds remain unexplored, for example, their enormous scientific value, which ranges from evolutionary, ecological and behavioural advances to biomedical research, where they are prominent in genetic studies, development of vaccines, and in the discovery and exploitation of retroviruses (Magurran, 1998).

Waterbirds occur in wetlands, often in spectacular concentrations, and are one of the most obvious indicators of the richness and evenness of these productive ecosystems. Bird species diversity reflects the diversity of habitats, altitudes and climates. Moreover, waterbird communities integrate food webs across the entire trophic levels, thus they can track changes in other indicators (e.g. invertebrates, vegetation, fish). They are known as a key indicator for monitoring the health of the water ecosystem.

The long migrations of some waterbirds have made these birds a favoured subject for research, survey, education and recreation throughout the world. Networks of waterbird censuses on every continent contribute to coordinatedwaterbird monitoring programmes, making waterbirds one of the most comprehensively studied groups of animals on earth (Wetlands International, 2006).

Migratory waterbirds pass through many wetlands in route to their breeding or wintering grounds. The wetland may still support internationally important numbers of a population because of the total number of birds which use the site during the whole migration period. This can only be substantiated by an estimation of the rate at which the individuals present are changing (Wetland International, 2005).

According to wetland international (2010), Africa hosts the third largest number of waterbird populations (542 species) although waterbird estimation, relative to other regions, is primitive, data quality are poor and waterbird conservation policy is in its early stage. Eritrean, as part of Africa, hosts 146 waterbird species, in which many of them are fresh water birds. Hence the paper made an attempt to undertake the research on waterbirds.

\section{Objectives:-}

- General Objectives

It is designed to study the species diversity and relative abundance of waterbirds in Maekel Zone.

- $\quad$ Specific Objectives

This research project is aimed to:

- $\quad$ Collect relevant data on the waterbird species diversity in Maekel Zone.

- Estimate the relative abundance of each species

- Determine the temporal and spacial variation of waterbird species in time and across sites Identify main threats to waterbirds and suggest possible solutions for future management strategies. 


\section{Significance of the Study:- Population Trend:-}

Effective conservation of waterbird population requires reliable information to be available on their current status in that it could:

- Improve understanding of species in their distribution range (including population sizes, annual cycle, movements and migrations) and help monitor change in certain parameters.

- Provide information to estimate and track population change through time.

- Prioritize conservation measures to be taken for threatened species.

- Contribute for complete waterbird checklist of the region.

- The present study will be useful in application for other areas to get the data.

\section{Site importance:-}

All waterbirds require network of high quality sites for nesting, refuelling during migration, and surviving the nonbreeding season. This study could:

- Highlight the role and importance of the site and the country's wetlands for different species of waterbirds in their annual cycle.

- Encourages continued monitoring of the sites by taking corrective measures.

- Promote evaluate the importance of the sites and set baseline information for conservation action and future study.

- Initiate identification of additional Important Bird Areas(IBA) in the region and the country.

\section{The Study Area:-}

Eritrea is an arid and semi-arid country, and is not endowed with rich water resources. Furthermore, being part of Sahelian Africa it has been the victim of recurrent and devastating droughts. It is also a country completely dependent on rain-fed agriculture. Rainfall in Eritrea is torrential, very unpredictable and occurs sporadically. There are a number of drainage systems in the country. All river systems are intermittent, except for the Tekeze-Setit which has perennial flow. There are no natural surface water bodies. A few dams are found in the highlands (Environment Department, 2006)

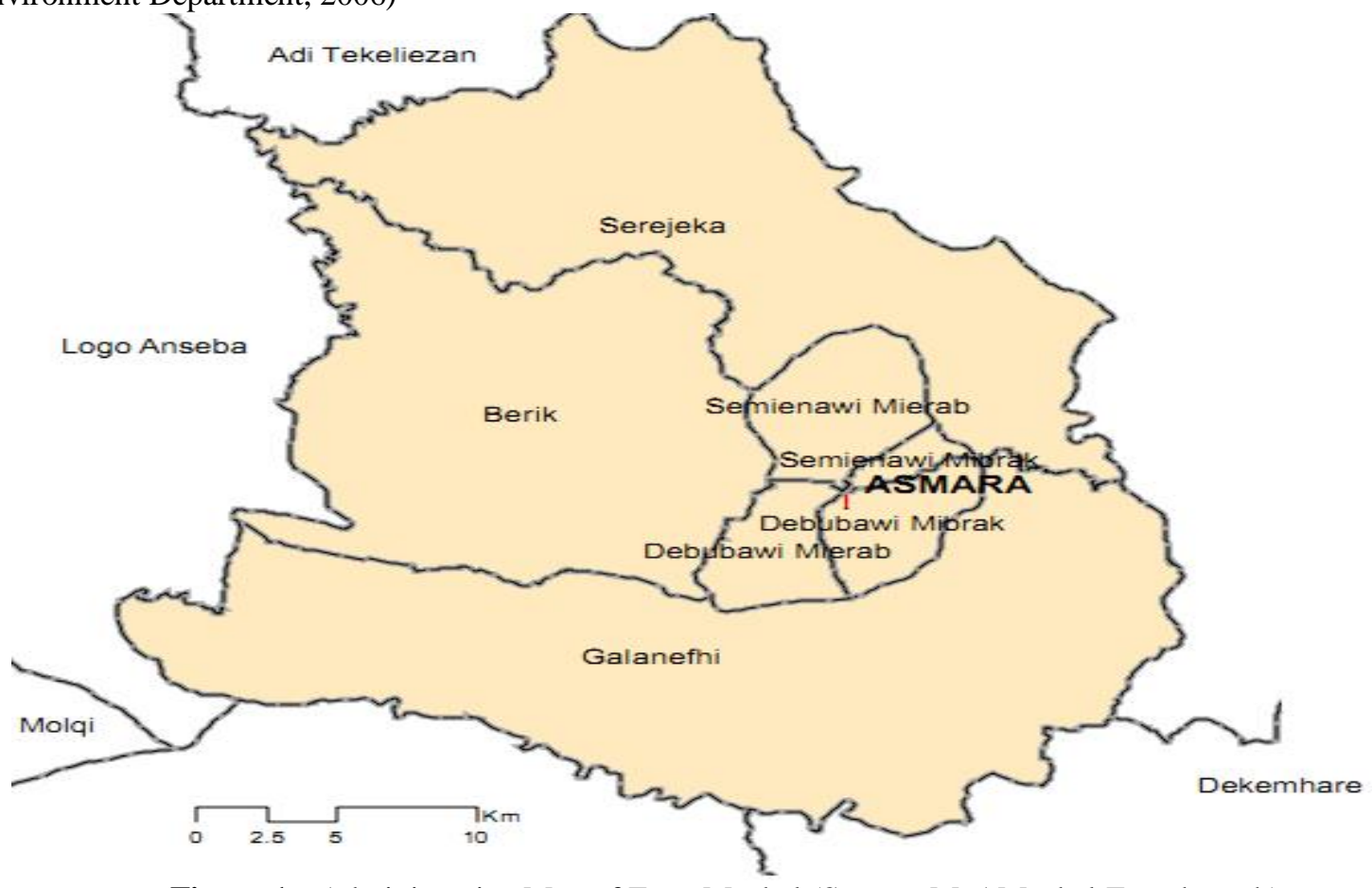

Figure 1:- Administrative Map of Zone Maekel (Source: MoAMaekel Zone branch)

Selected Sample Dams and Reservoirs in Maekel Zone were the specific sites where the present study was conducted. Zone Maekel is one of the six administrative regions (Zones) of Eritrea. It is the smallest region in the 
country with a total area of $1,040 \mathrm{~km}^{2}$. It is located in the central part of the country with longitude of $38^{0} 41^{\prime} 36^{\prime \prime}-$ $39^{0} 3^{\prime} 00^{\prime \prime}$ East and Latitude $15^{\circ} 34^{\prime} 36$ North at an altitude between 1276 to $2625 \mathrm{~m}$ above sea level.

The Zone is divided into 7 Sub-Zones (Figure 4) with 59 administrative regions and 89 villages. It is densely populated with $27 \%$ of the population is engaged in traditional agriculture (ZMA, 2009).

The climatological data available for Maekel Zone shows that the Zone's rainfall is generally inadequate and unreliable. The main rainy season is between June and August with short rains between March and May. An annual rainfall record from MoAMaekel Zone shows that the mean annual rainfall during 1997 to 2007 was $418 \mathrm{~mm}$. The mean maximum and minimum annual temperature are $25.5^{\circ} \mathrm{C}$ and $4.3{ }^{\circ} \mathrm{C}$ respectively (Kifle and Randcliffe, 1997).

The Zone is not endowed with natural vegetation, except for the community plantations of eucalyptus trees and some pockets of natural forests with small bushes and shrubs. Most of its area is deforested and degraded by water and wind erosion. In the small pockets of natural vegetated areas that exist, mainly in SubZonesBerik and GalaNefhi, the dominant trees and shrubs include Acacia tortilis(a'lla), Acacia etbaica(Seraw),Dednaeaangustifolia (Tahses), Eucleaschimperi(Kilaw), Beciumgrandiform(Tahbeb), and Rumexusambarensis(Hehot).Most of the community plantations, found especially in Sub-Zone Serejeka, are dominated by Eucalyptus and Acacia species (Woldeamlak\& Haile, 2012).

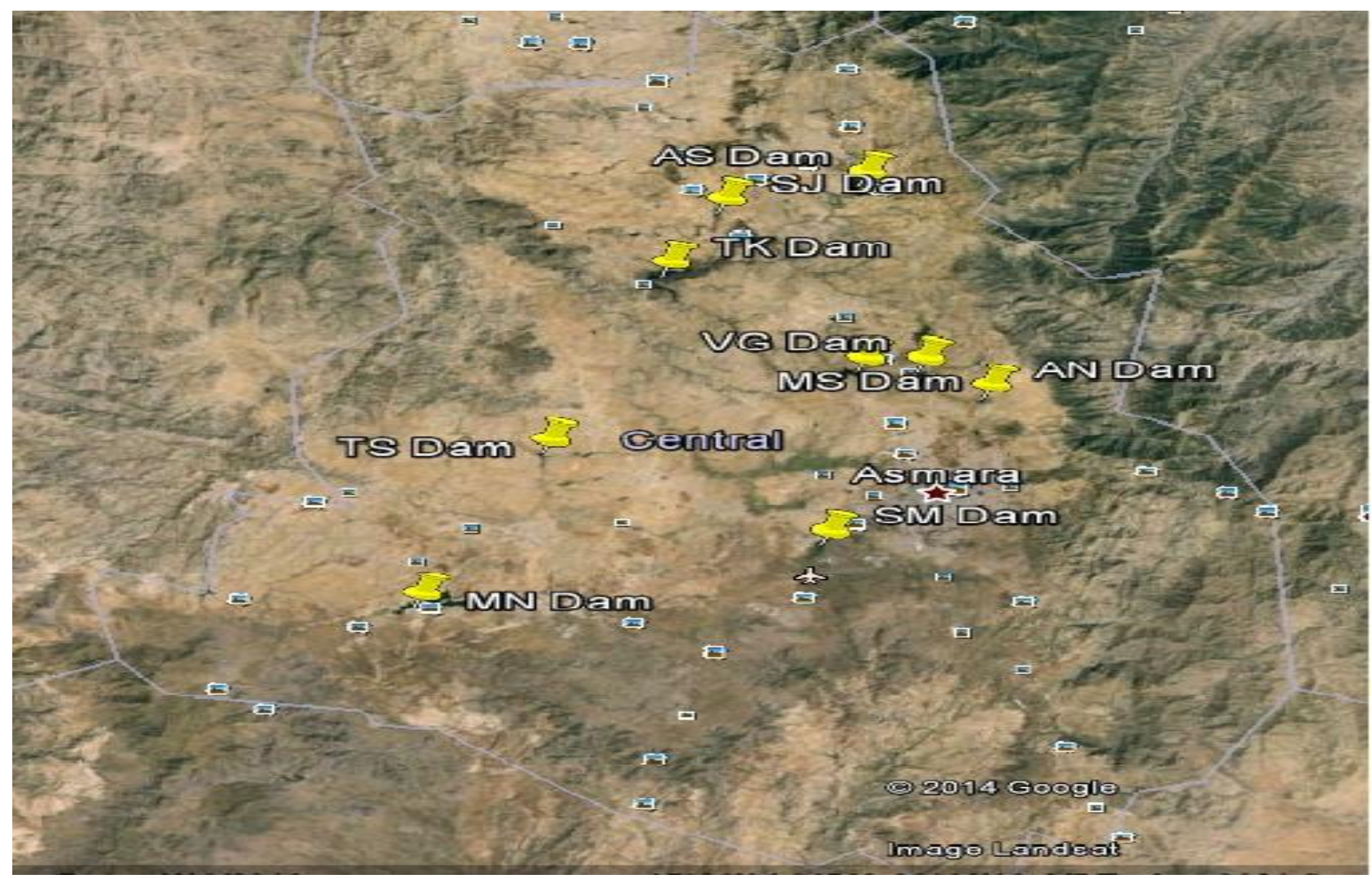

Figure 2:-Map Showing the Specific Study sites (Dams) in Maekel Zone (Source: Google Earth)

There are 74 Dams and reservoirs within the Zone (Figure 5) with an aggregate water holding capacity of 67 million $\mathrm{m}^{3}$ (MoA, 2010). Some of these are used mainly or exclusively for Asmara Town water supply. The other reservoirs are used for irrigation, livestock watering and rural water supply, including domestic supplies (Abraham, Filmon\&Selemawit, 2009).

Several dams and reservoirs were visited and, later, nine (9)dams were selected for the present study (Fig. 2). Note that there are no major/big rivers in the Zone that can be included in the present study. The selection was based on the size of the water bodies(Water capacity), previous history of birding, identified as IBA, hosts threatened 
waterbirds(locally, regionally or globally) and, most importantly, their variation in richness of fish and vegetation complexity of the shore area related in productivity.

\section{Research Design:-}

During the preliminary survey, spots have been predefined purposively at intervals.Here, the site was covered systematically traversing on foot. When choosing a route, general thought has been given to the light conditions (birds are easier to see with the light behind you) and the risk of disturbing flocks of birds.

Multiple counts were made to all study sites at an interval of roughly one and half months, i.e. each site has been visited three times to explore information on temporal and spatial variation. Birds flying overhead were generally not counted. Video recording and photographs were taken for further confirmation.

When to count water-birds:-

Generally, the survey was conducted during morning hours (9-12 am) and afternoon hours (15-18 pm) when birds are most active. Transects were walked at a pace that allows the researcher to cover the whole study area, approximately, in about 90 minutes. This helps to avoid double count. Unavoidable interruptions may occur during the survey. In such case the survey has stopped and then continued after the interruption has settled.

\section{How to count water-birds:- Starting the Count:-}

A general strategy for waterbirds count has been developed prior to the actual survey. The team approaches the survey location quietly. Once arrived at the beginning of the survey route, the team waited for 2 minutes before starting recording birds. Here the observers were travelled on the same route on each visit, along the transect, and stopped at pre defined spots, allow the birds time to settle(1-2 min), scan with binoculars and then record all the birds seen or heard. At the starting point, any birds that where flushed from the transect area were recorded.

\section{Counting the Birds:-}

Once the survey has started, the team counted the number of birds (for each species) heard or observed within the predefined transect points. Here a preliminary scan was made with binoculars and the overall number of birds and the proportion of each species was rapidly assessed, in case disturbance or some other factor causes the birds to fly away before the team has completed more detailed counts. For some birds, codes were used to mark down the birds during the survey for later transcribe to the full common name and, sometimes, later identification. After a count is completed, the team immediately identifies all birds whose identity was in question.

To reduce biasness, the team were:

- Using the same or similar equipment

- Visiting and spending roughly the same time at the site

- Using the same means of transport

- Covering the same area

- Following the same route

- Stopping at the same points

- Using the same method of counting or estimating

\section{Data Collection:-}

Throughout the survey, birds were observed, identified and counted using whole area search technique. Here, birds were observed within a short distance using a binocular $(10$ x 50 magnification power) by walking along the predefined spots.

The whole Area Search is a quantitative, habitat specific survey method that is widely applicable in most habitats. It is useful for diversity measurements such as species richness, relative abundance of each species, as well as provides information on avian-habitat relationship. Generally, the following variables were intended to investigate: Species type, its abundance and main threats that may exist in the area based on the assumption that common birds are on average more likely to be seen first and rare birds may take longer to find.

\section{Data Analysis:-}

Biological diversity can be quantified in many different ways. When measuring diversity, species richness and evenness were taken in to consideration. 
Richness is the simplest measure of species diversity. It is a measure of the number of different kinds of organisms present in a particular area. The more species present in a sample, the 'richer' the sample is. Species richness takes no account of the number of individuals of each species present. It treats rare species and common species equally. Thus, diversity depends not only on richness, but on evenness also.

Evenness is another and more useful concept of species diversity. It is a measure of the relative abundance of the different species making up the richness of an area. It compares the similarity of the population size of each of the species present.

CAP-4 and SDR-4 were used to analyse the data obtained in to the following indices.

Whittaker Plot

The Whittaker (1965) plot is a graphic method combining species richness and abundances of the various species in a standard plot of species abundances, with log-relative abundance (Y-axis) and arithmetic species ranks (X-axis). It is a visualisation of community organization related to the relative abundance of the different species in the community.

\section{The Shannon-Wiener Index of Diversity:-}

$$
\begin{array}{r}
\mathbf{H}=-\sum\left[\left(\mathbf{p}_{i}\right) \times\right. \\
\text { Where: } \mathbf{H}=\text { Habitat Diversity Index(Shannon-Wiener Index) }
\end{array}
$$

$\mathbf{p}_{i}=$ proportion of total sample represented by species $i$

$\mathbf{S}=$ number of species, $=$ species richness

Two components of diversity are combined in the Shannon-Wiener function, number of species and equitability or evenness of species. In practice, the Shannon-Wiener Index, H, ranges from 1-low diversity- to 5-high diversity in most studies, increasing with the number of species in the community. The Shannon-Wiener function gives more relative weight to the rare species in sample. Thus, a greater number of species increases this index of species diversity. Moreover, a more even or equitable distribution of individuals among the species also increases the Shannon Wiener Index.

\section{The Simpson's Index of Diversity:-}

Simpson's Index of Diversity measures the probabilities of picking two individuals at random that are different species. As species richness and evenness increase, so diversity increases. Simpson's Diversity Index is the measures of diversity which take into account both richness and evenness. The following estimator was used to estimate Simpson's Index of diversity.

Simpson's Index of Diversity $(\mathbf{1}-\mathbf{D})=1-\sum \mathbf{n} i(\mathbf{n} i-\mathbf{1})$

$\mathbf{N}(\mathbf{N}-1)$

Where: $(\mathbf{1}$ - D) $=$ Simpson's Index of Diversity

$\mathbf{n}_{i}=$ Number of individuals of species $i$ in the sample

$\mathbf{N}=$ total number of individuals in the sample $=\sum \mathbf{n}_{i}$

Simpson's Index gives less weight to rare species and more weight to common species. It ranges from $\mathbf{0}$ (no diversity) to a maximum of $\mathbf{1}$.

\section{Simpson's Measure of Evenness:-}

For Simpson's measure of heterogeneity, maximum diversity is obtained when all abundances are equal. The maximum possible value of the reciprocal of Simpson's Index (1/D) is always equal to the number of species observed in the sample. This leads to a simple definition of Simpson's Index of evenness.

Where $: \mathbf{E}_{1 / \mathbf{D}}=$ Simpson's measure of Evenness

$$
E_{1 / D}=(1 / D) / S
$$

$\mathbf{D}=$ Simpson's Index $=\sum \mathbf{n} i(\mathbf{n} i-\mathbf{1})$

$\mathbf{N}(\mathbf{N}-1)$

$\mathbf{S}=$ number of species in the sample 
The index of evenness ranges from $\mathbf{0}$ to $\mathbf{1}$ and is relatively unaffected by the rare species in the sample. In this case, the index represents the probability that two individuals randomly selected from a sample will belong to different species.

\section{Simpson's Index of Similarity:-}

Measure similarity between communities based on species composition. Useful in comparing community's composition changes over time, or even composition similarity between sites. Values range from 0 to 1 with the higher value suggesting greater similarity.

$$
\operatorname{Sim}=\frac{2 \sum n c}{\sum n 1+\sum n 2} \quad \begin{aligned}
& \begin{array}{l}
\text { Where: } \boldsymbol{n c}=\text { the common species between sites; } \\
\mathbf{n} \mathbf{1}=\text { the species of site one } \\
\mathbf{n} 2=\text { species of site two }
\end{array}
\end{aligned}
$$

Materials Used:-

Correctly identifying all the waterbird species present at a site is the first necessity of waterbirds counting. Correct identification includes a process of elimination, and knowing which species are most likely occur at a site in a particular season and habitat reduces the number of species that need to be eliminated from consideration.

During the study period the following materials were utilized:

Binoculars:-binoculars with magnification power of 50x10 were used to enable correct identification and accurate counting of waterbirds encountered.

Identification Guide:-helps to identify birds properly. A book "Bird of Africa, South of the Sahara" by Ian Sinclair and Peter Ryan as used to identify bird properly.

Digital camera:-Used for documentation.

Data sheet: data sheet has being employed during the whole bird survey to record bird counts. GPS: used to measure elevation and identify the co-ordination of the study areas .

\section{Results:-}

General observations were made whenever possible to contribute for the production of a complete waterbird checklist for Maekel Zone. Waterbird records for the country are being compiled from wetland international to help and serve as a base for the project and water bird count from each visit were compiled.

The waterbird record based on several surveys carried out during the study period, November 2013 to March 2014 , is presented. A total of 38 waterbird species were recorded in the study area during the whole period (Table 4 and Figure 3) which represents about $26 \%$ of the total 146 wetland-dependent birds found in Eritrea. The highest waterbird species (23) were recorded in Valle-Gnocchi dam during the third trip, which comprises more than $60.5 \%$ of all the species recorded. Only seven (7) species, the lowest number, were recorded from Serejeka dam during the second visit. Most of the dams scored from 9 to 15 species in all visits throughout the study period (Appendix 2, 3 and 4). In the first trip, 29 species were recorded, with six unique species to it. In the successive $2^{\text {nd }}$ and $3^{\text {rd }}$ surveys, a total of 25 and 28 species were recorded respectively. Great Snipe, White Stork and Black-Headed Gull are encountered only once in the second survey. Moreover, six new waterbird species(Table 6) are recorded in the third trip only, mostly represented by few individuals, usually 1 to 5(Appendix 4). The rest 23 species are common and encountered two or more times during the whole study period. In general, the total number of species counted was higher in each of the dams rich in submerged vegetation cover, and with shallow, flat, muddy and swampy shoreline area surrounded by irrigated farmland in comparison to the open dams with no vegetation cover and steep shoreline dams. In all areas, the number of species observed was relatively lower at the second survey (Table 4). These changes may be coincided with the northward migration of polar-arctic species.

In the first survey, the total number of species recorded was higher in the Sembel and Adi-Sheka dams compared to the rest, 15 and 14 species respectively (Table 4). Species richness was much higher in the Adi-Nefas and ValleGnocchi dams, each scores 17 species, in the second survey. The difference in species richness between the dams decreased, however, in the third survey. Valle-Gnocchi, on the other hand, scores the highest waterbird species, 23 
in total. Moreover, several species were common to all dams so that only 38 bird species were observed throughout the study period.

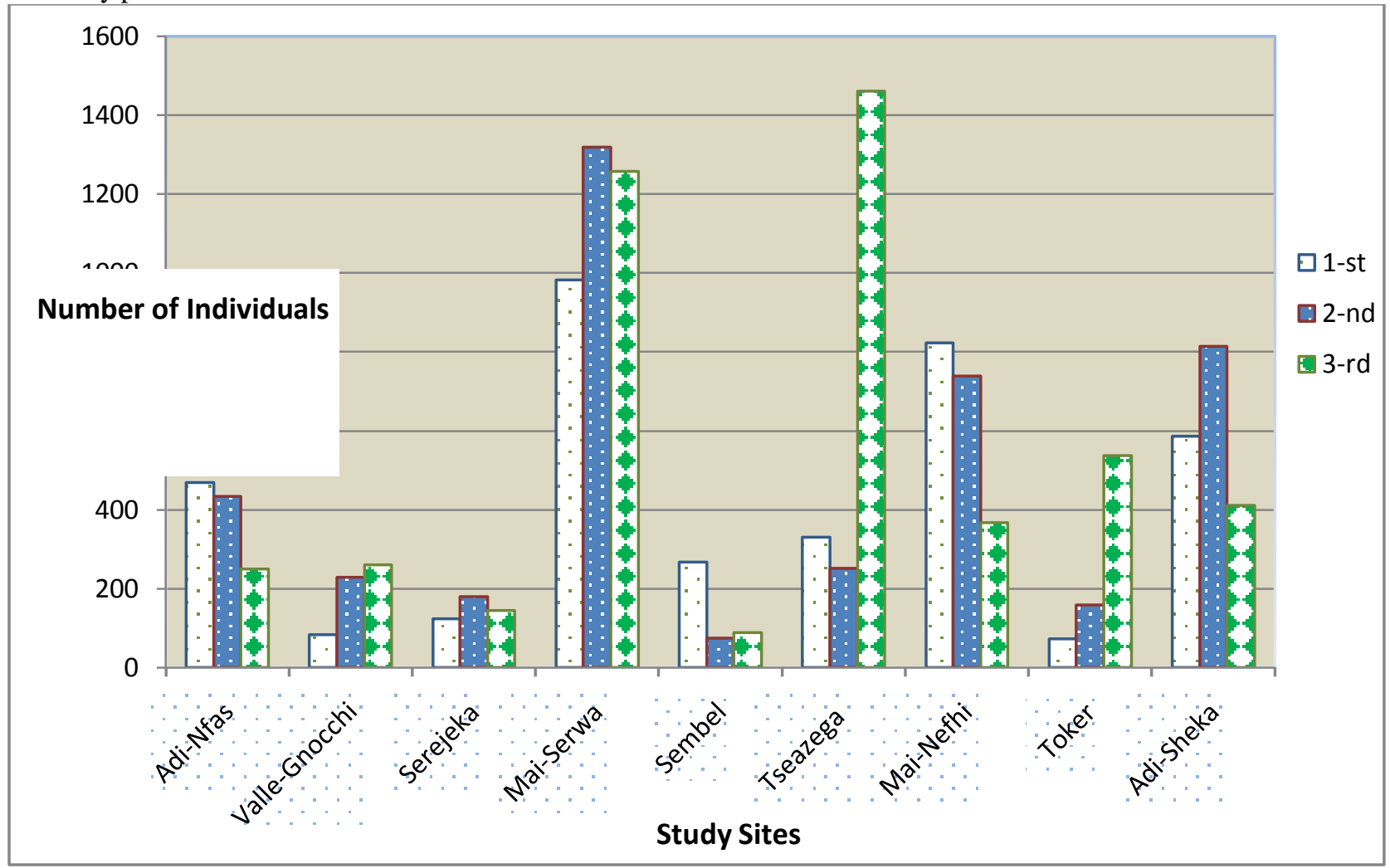

Figure 3:-Number of Individuals Counted at each site per visit.

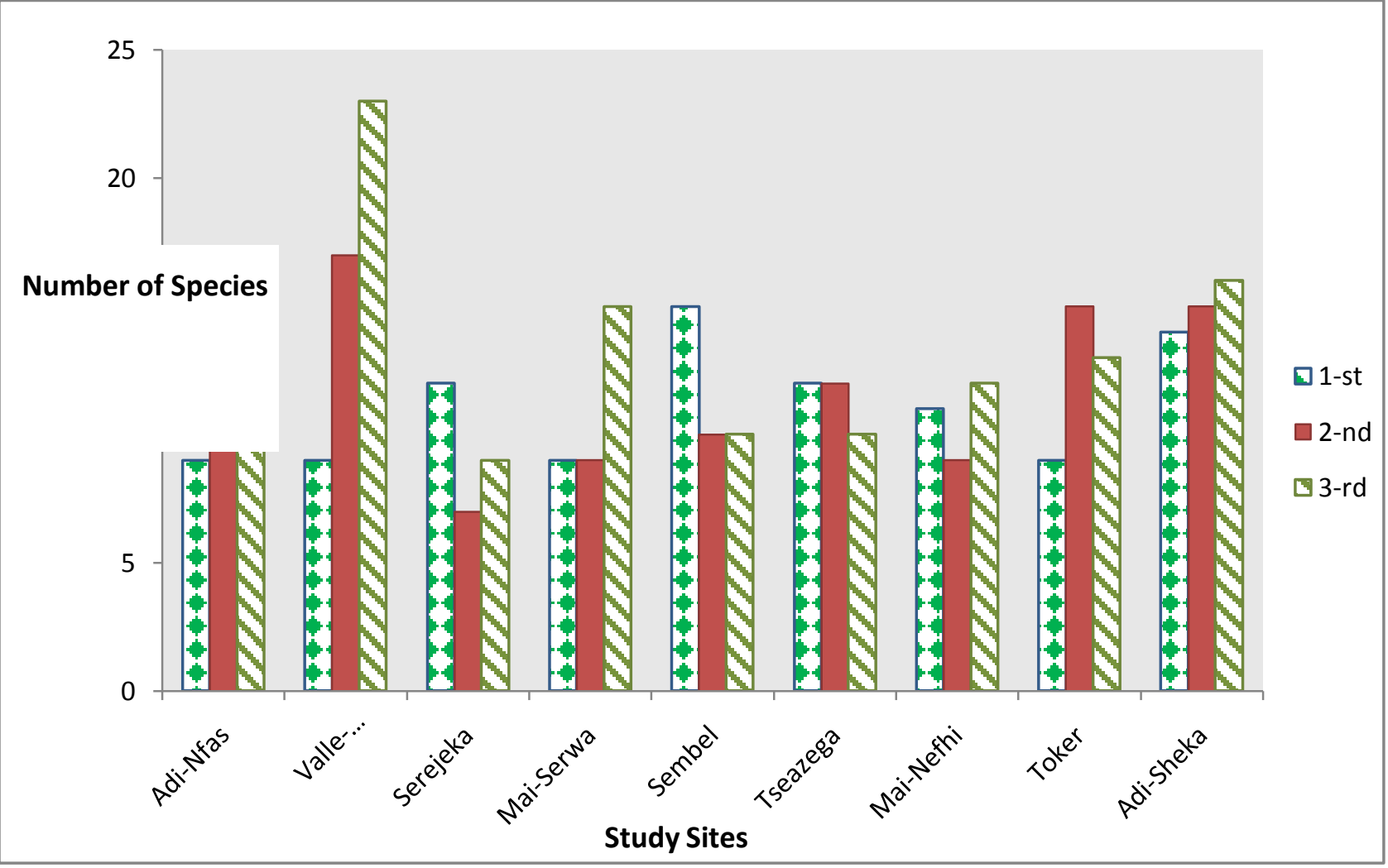

Figure 4:-Number of Species Counted at each site per visit. 
Interestingly, the total number of individuals counted in Mai-Serwa(3559 individuals) is much higher compared with that of Sembel, Valle-Gnocchi and Serejeka dams, which constitutes about $28 \%$ of all individual birds recorded(Table-4). Tseazega, Mai-Nefhi and Adi-Sheka scored the next highest number, roughly around 2000 individuals, and Adi-Nefas dam scores 1151 individuals. The number of individuals counted shows decreasing trend in Sembel, Adi-Nefas and Mai-Nefhi while it shows marked increment in Tseazega dam and slight increase in Toker dam. In contrast, the number of individuals was fairly consistent in Serejeka, and Mai-Serwa dams in all the survey times, where there seemed to be a continuous replacement of individuals that moved in and out of the area roughly in equal number. Thus, during migration period, some waterbird species were replaced by others, sometimes in large numbers (Appendix-1).

Generally, a total of 12713 individuals were recorded, grouped in to 38 different species, throughout the study period, out of which 4778 individuals were encountered in the third survey, which constitutes about $38 \%$ of the total number. Thus, the number of individual recorded shows clear increasing trend (Table4).

Table 1:-The total number of species and individuals recorded in Respective study sites.

\begin{tabular}{|c|c|c|c|c|c|c|c|c|c|c|}
\hline \multicolumn{11}{|c|}{ Study Area/Habitat Types } \\
\hline & 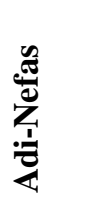 & 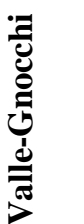 & 晃 & 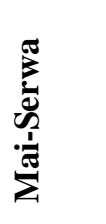 & $\begin{array}{l}\bar{\Xi} \\
\bar{\Xi} \\
\mathscr{\nu}\end{array}$ & 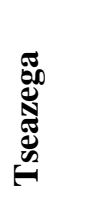 & 光 & 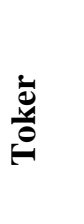 & $\begin{array}{l}\frac{\pi}{2} \\
\frac{\pi}{d} \\
\frac{2}{2} \\
\frac{1}{2}\end{array}$ & 豙 \\
\hline Survey & \multicolumn{10}{|c|}{ Number of Species Counted } \\
\hline $1^{\text {st }}$ & 9 & 9 & 12 & 9 & 15 & 12 & 11 & 9 & 14 & 29 \\
\hline $2^{\text {nd }}$ & 17 & 17 & 7 & 9 & 10 & 12 & 9 & 15 & 15 & 25 \\
\hline $3^{\text {rd }}$ & 15 & 23 & 9 & 15 & 12 & 10 & 12 & 13 & 16 & 28 \\
\hline \multicolumn{11}{|c|}{ Number of Individuals Counted } \\
\hline $1^{\text {st }}$ & 469 & 84 & 123 & 9983 & 268 & 3330 & 823 & 73 & 586 & 3739 \\
\hline $2^{\text {nd }}$ & 433 & 229 & 179 & 1319 & 74 & 251 & 738 & 159 & 814 & 4196 \\
\hline $\mathbf{3}^{\text {rd }}$ & 249 & 261 & 145 & 1257 & 88 & 1461 & 368 & 538 & 411 & 4778 \\
\hline Total & 1151 & 574 & 447 & 3559 & 430 & 2042 & 1929 & 770 & 1811 & 12713 \\
\hline
\end{tabular}

\section{Species-Abundance Relationship:-}

In all dams, few species, seven or eight, occurred in large number(> 50 individuals) while the number of species represented by 1 to 10 individuals was very high(Figures $3, \& 4$ ). This trend was consistent throughout the study period even after the migration period. Such a trend is common in bird communities (Krebs, 2000).

Out of 38 species observed, only six (6) species were represented by $\geq 100$ individuals in either of the visits, and another seven (7) species were characterised by individuals between 50 and 100. Moreover, the total number observed for many species is still relatively low. Thus, only 12 species had some of individuals $>200$. Surprisingly, the number of species who were represented by five(5) or less individuals in all successive visits is 14 , and 12 of them score a total of $\leq 5$ individuals throughout the survey as shown (Table 1).

Of all the total individual waterbird populations, 12713individuals, observed during the whole census period, $72 \%$ are belongs to Egyptian Goose, which is extremely high. Thus, Egyptian Goose is the most dominant species. Similarly the number of Northern Shoveler and Pink backed pelicans were relatively high in the study area, $4.7 \%$ and $4.2 \%$ respectively. Little Grebe ranked fourth in the population size recorded among the 38 species. Moreover, the number of Ruff, Red knobbed Coot and Grey Heron in the study area is promising. Raw data are given as Table 1 .

The trend with a few common species and many species represented by few individuals seemed not to be strongly influenced by species turn-over. In almost all the dam, certain species moved out of the area and others either moved into the area in large numbers, or if already represented by a few individuals, increased in abundance. Valle-Gnocchi dam, for example, in the first survey nine species were recorded, mostly represented by few individuals, and later a 
strong increase in species richness and abundance was seen. Similar observations were also made in most of the dams (Appendix 2-4). Relative to their size, Tseazega and Mai-Nefhi dams were poor, next to Serejeka dam, compared to the other areas. Sembel dam scored the lowest number of individual birds (430 birds) throughout the study period roughly equally distributed among 15 species (Table 1).Thus, all species are equally likely to be encountered. Generally, only few species appears in dominant number and majority are represented by few, sometimes below 5 , but consistent number of individuals.

\section{Discussion:-}

Generally animal life is, on the whole, more abundant and varied in the tropics (latitudinal gradient). Similarly small or remote islands have fewer species than large islands or those nearer to continents. The regularity of such pattern could be climate, productivity, disturbance, and spatial heterogeneity. Naturally wetlands are more diverse, because they provide a large variety of both food and breeding sites for the organisms and improve survival during the nonbreeding season.

Animals and man have a long history together through human's domination and use of the environment for different purposes. The study of waterbirds of a specific water bodies is very important in determining the importance of water bodies and the impact of human action on bird's diversity and abundance. This can be studied through a regular basis of bird count in relation to the flow of food and nutrient energy, and the exchange of materials between the organisms and the physical environment.

There are 74 dams and reservoirs in total in Maekel Zone(Since 2014), in which some of them are used for small scale irrigation farming, livestock watering and household activities, and some others protected and are used exclusively for Asmara city water supply. In dams, like Sembel and Adi-Nefas, irrigation and crop rotation, in small scale, appears to be common agricultural practices. This study compared diversity and relative abundance of waterbirds in dams with different ecological status and practices.

\section{Species-Abundance Relationship:-}

Biodiversity of an area is not determined by number of species found in the area only. Thus, the abundance of each species is also important to consider. During the whole survey only few species, not more than eight, occurred in large number(> 50 individuals) while the number of species represented by less than 50 individuals was very large, many of them scored 1 to 10 individuals only(Appendix 2 to 4 and Figure 10, $11 \& 12$ ). This trend was consistent throughout the study period even after the migration period in March.

The trend in which few common species and many species represented by few individuals were not influenced, usually, by species turn-over. In all the visits species turn-over was seen in almost all the dams. Thus, certain species moved in and out of the area and others either moved into the area in large numbers or increased in abundance. Valle-Gnocchi dam, for example, showed sharp increment in species number (23 species) in the third survey compared to nine species recorded in the first survey, mostly represented by few individuals. Similar observations were also made in most of the dams (Appendix 2).High consistency in species abundance was noticed during the study period, especially in the larger dams. This was, probably, because the food availability of the dam was more or less unchanged, which may be related to the water volume did not change as much as it did in the other small dams.

Relative to their size, Mai-Serwa, Tseazega and Mai-Nefhi dams, and even Toker and Adi-Sheka dams, were generally poor in species composition compared to others. The abundance was not uniform in all species. Thus, few species dominated the area, mostly Egyptian Goose. This was probably because the topography of the dams do not motivate for shore birds in that the shoreline is comparatively steep and rocky. Moreover, these dams had large surface area that reduces competition and disturbance. It was more typical to swimmers, since birds require enough space. The remaining dams had relatively fair abundance among the species recorded. Sembel and Serejeka record the lowest number of individual birds (430 and 447 birds respectively) throughout the study period (Table 1).

A total of 38 species, composed of 12713 individuals, were observed throughout the survey period. Interestingly Egyptian Goose was the most abundant, which comprised 72\%, followed by Northern Shoveler (4.7\%), PinkBacked Pelican (4.2\%) and Little grebe. Generally, the number of Egyptian Goose showed a very little fluctuation and remained relatively constant. Usually these birds were not encountered in small ranged dams, like Sembeldam.Moreover, the number of Little Grebe,Ruff, Red knobbed Coot and Grey Heron, relative to other 
species, was also encouraging (Table 1). White Stork and Scuaco Heron were represented by two individuals. Great Snipe, Black Headed Heron and Black Headed Gull were the least abundant, each represented by a single bird.

\section{Species Richness:-}

During the study period, the temporal and spatial variations in diversity of waterbird species were recorded relative to time and across sites. Most dams scored highest species count in the third survey (Table 1), although the total number of species observed was roughly equal to the previous. This was probably because as the water level/volume decreases, fish accessibility to birds increases. Moreover, the shallow shores of the dams facilitate foraging by many species of waterbirds, especially short legged shorebirds. Fishes were known to become the main source of food for many waterbirds, such as pelicans which frequently occurred in most dams in the third survey.

Many migrating species of waterbirds left the area and replaced by others, for example Maccoa duck, Northern pintail, Green sandpiper and Pied Avocet. Thus, it was observed a certain turnover of species (Table 1). This might suggest that migrating birds such as waders and other species were using the dams either as stop-over, to refuel during the long migration, or wintering ground to overcome drought in the breeding area. Moreover, it is possible that by coming to the area the birds would experience less competition than they would have done in other water bodies.

In most dams, there was a marked difference in species richness and abundance from $1^{\text {st }}$ to $3^{\text {rd }}$ survey, though there was no clear trend. Serejeka dam scored few species during the last two visits. This was probably due to high disturbance. The dam was intensively used for livestock watering, grazing, washing clothes, swimming and domestic activities, especially when crops were harvested. Sembel and Valle-Gnocchi dams, on the other hand, showed a marked increment on the third visit. These dams were relatively calm and rich in food resources. The nearby irrigation farm may contribute to the productivity of the dam, which was believed to provide food for different bird species. Thus, the highest species number (23) was observed in this area.

The species diversity index and evenness of habitats during the entire survey revealed that Sembel dam had the highest species diversity and evenness, followed by Valle-Gnocchi and Adi-Nefas dams respectively (Table 1). This indicates that although the total number of individuals observed, especially in $2^{\text {nd }}$ and $3^{\text {rd }}$ visit, was relatively low (Table 1), the number of species scored in the area was high. This is probably explained by that the dam was dominated by submerged vegetation, potamogeton species, and was characterised by shallow, flat and muddy shoreline (Figure-4). Thus, it supports many wetland birds, mostly with short legs, of little Grebe, different species of Plovers and Ducks appeared to feed on invertebrates. During the survey times, birds were observed foraging mainly in the vegetated areas of the dams. It was very likely that many invertebrates were found particularly in the vegetated areas of the dam. Here there was a continuous high production of food for seed and insect eating waterbirds. Moreover, the vegetation provides nest material and support for the floating nests. This is typical for the breeding species of Red-Knobbed coot, Shoveler duck and little grebe. Similar observation was made in ValleGnocchi dam, which possess very similar ecological features and supports many waterbird species, mostly shore birds. More interestingly, Sembel dam host six waterbird species which were not found in other dams, encountered once or twice. Moreover, Black Headed Heron, White Stork and Black Headed Gull were recorded from ValleGnocchi dam (Table-1).Maccoa Duck, globally threatened, and Great Snipe were observed only in Adi-Nefas Dam as Pied Avocet was to Tseazega dam throughout the study period (Table1).

Compared to Sembel dam, Mai-Serwa dam scored the least index of both Shannon-Wiener and Simpson's indices, relative to the highest number of individuals observed. The shoreline is mostly rocky and, sometimes, steep.

The surface area of Mai-Nefhi, Toker, Mai-Serwa and Adi-Sheka dams was relatively large. Nevertheless highest species richness was observed in the relatively small dams (Table 1). Thus, it is not always the size of water surface area that determines the bird diversity. Food productivity could be one important factor, which depends on the spatial complexity as well as the availability of nutrients for the first trophic level. The second reason was, probably, the topography of the dams, which affects the foraging activity of birds. The shoreline of most dams was comparatively steep, which would make it difficult for short-legged and small shorebirds to exploit the food resources. 
In general, the total number of species counted was high in each of the dams, usually small in size, rich in submerged vegetation cover with shallow, flat, muddy and swampy shoreline area, combined to the irrigated farmland areas, in comparison to open dams with no vegetation cover and steep shoreline (Table 1).

\section{Evenness:-}

The evenness of species in sites ranges from 0.05 to 0.91 , with majority lies between 0.35 and 0.65 . There was no a clear trend in the distribution of evenness in all dams except few. Sembel dam scored the highest evenness indices in all the visits with maximum of 0.91 in the third visit(Table 5). This was mainly because the area contained all the different species in almost equal numbers of individuals. That is, a more equitable distribution of individuals among the species has shown in the site. The three indices indicate that Sembel dam had the highest diversity. Thus, the indices corroborate the impression gained during the visits to the area .In general, Adi-Nefas, Valle-Gnocchi, Sembel, Mai-Nefhi and Adi-Sheka areas showed a gradual levelling off of the differences in population numbers of the different species in the third visit. The evenness indices obtained for the Adi-Nefas, Mai-Nefhi and Adi-Sheka dams reached the highest values on the third visit. This meant that, there were no pronounced differences in numbers between the different species. Toker and Tseazega dams scored high Simpson's indices, 0.78 and 0.58 respectively, in the first visit and then gradually decreases in all the visits to 0.24 and 0.19 respectively (Table 1). There were large differences in the number of individuals count between the species in Toker and Tseazega dams (Table1) as indicated by the low values of the indices for these areas(Table1). This is explained by that as the water level decreases in winter, the shoreline of Toker dam become very steep and rocky, which hinders short-legged Shorebirds for accessing it. Here, the dam was dominated by swimmers, mainly Egyptian Goose. Similarly, Tseazega dam showed a pronounced decrease in water level and range contraction in the third trip. This leads to high disturbance by the villagers, as they intensively use it, which keeps shorebirds away. It was highly disturbed area, next to Serejeka dam, that even the Egyptian Goose and Pink Backed Pelicans, the most dominant species in the area, do not roost and feed regularly. They visit the area in a specific time of the day, usually early morning or late afternoon, to avoid disturbance.

Mai-Serwa dam scores the lowest index of evenness (0.05), relative to other sites, in all the visits (Table 1). The dam showed almost similar indices for all the visits i.e. all the time the area was seen dominated by few species and many species were represented by a few individuals for the same reason as Toker dam. For example, the highest number of individuals was observed in the area at the second survey, 1319 individuals in total, represented nine species only. Majority of the individuals scored were belongs to one species, the Egyptian Goose (98\%). Similar trend was not clear in Adi-Sheka and Valle-Gnocchi dams.

\section{Similarity Between Sites:-}

Simpson's Similarity index between the sites was calculated. The index ranges from 0.50 to 0.91 . It normally varies from 0.60 to 0.80 and rarely exceeds 0.85 (Table 1 ). This shows that the species composition in most of the sites was very similar. This similarity may be due to the resemblance of the habitats. Relative to others, the highest similarity, 0.91, was scored between Serejeka and Tseazega dams. Thus, the two dams host similar species of waterbirds. During the survey, it was observed that the physical feature of the sites was very similar. Both are open areas and surrounded by seasonal agricultural fields. Moreover, they are highly disturbed sites due to uncontrolled man activity for fetching water and grazing animals.

\section{Threats to Waterbirds in Maekel Zone:-}

Waterbirds in Maekel Zone face a number of threats of small scale fish farming, habitat destruction, sedimentation and agricultural conversion, human disturbance, water pollution and eutrophication, partially. Reservoirs have limited life because they eventually lose their storage capacity due to uncontrolled sedimentation. In Eritrea the useful lifespan of the medium and small dams, under ideal conditions, is in the range of 15 - 20 years (Negassiet al., 2002). From the general survey and observation, it was clear that many reservoirs were prone to sedimentation problems though no qualitative figure. This was probably because the catchment area is mainly farmland which is susceptible to erosion. Though no recent water quality data available, it was observed that the quality of water was worse in most dams due to increasing use of chemical fertilizers and pesticides in the upstream agriculture fields, especially Sembel and Valle-Gnocchi dams. Many dams are used as source of water supply for Asmara city, thus Chlorination reduced the productivity of the dams by changing its normal $\mathrm{pH}$. This was more evident in Mai-Nefhi dam. 
Garbage deposition along the shoreline was found to be a major problem in Sembel dam. More over, the deposited dam shore was being encroached by local people for agricultural conversion.

Human disturbance was identified as the major threat to birds. Most dams were regularly used for domestic activities, bathing, livestock watering \&grazing and agricultural activities. Moreover, fish farming caused enormous disturbance to the birds in most dams, even though fishery has enormously supported the livelihoods of the people. Potamogetonpusillumhas rapidly covered the water surface of the shore in Sembel and Valle-Gnocchi dams reduced the feeding areas for shore birds.

\section{ConclusionandRecommendations:-}

\section{Conclusion:-}

The survey showed that the dams, whatever the size, are important for varieties of water bird species including internationally threatened ones. They are important source of food and water for both migratory and resident bird communities.

There were large variations in the diversity of birds as well as the number of individuals among the study sites. Comparatively, Sembel dam was the richest area for birds both in diversity and abundance. It is not the surface area of the water body; rather it is the dam's capacity to supply the necessary resources that determined the species richness and relative abundance of bird species.

Generally, Egyptian Goose was the most abundant birds in the region. High consistency on abundance was observed during the whole study period.

There was much dynamics in the diversity of birds, some times in a very large number (Table1), caused by the amount and type of food present in an area at a particular time. However, the abundance of birds was not affected by species turn-over.

The survival of these wetlands and associated ecological services was under threat by unsustainable practices. Draining and pumping for small scale irrigation, expansion of farming toward the edge of the dam and grazing were major threats.

\section{Recommendations:-}

Maekel Zone is rich in waterbirds, representing at least $26 \%$ of total wetland-dependent birds of Eritrea. More water bird species can be expected in the region. A detail further survey should be carried out in the entire water bodies and surrounding farmlands to produce accurate estimates of species abundance and prepare a comprehensive waterbird checklist in the region.

Farther study is required to assess the role of irrigated farmlands in proximity to the water bodies in maintaining waterbird diversity, and the impact of various activities.

Eritrea is very important as a migration route and stop-over location for many species of Palearctic migrants. Moreover, it hosts threatened species, like Maccoa Duck (Oxyuramaccoa). Thus, it is important to protect areas like Sembel dam as national bird fauna to support and sustain the existing bird populations and eco-tourism activities.

Anthropogenic factors are the root causes for disturbance and habitat destruction of waterbirds. Conservation education and awareness programmes are essential for local farmers, students and visitors. Publication of factsheets, checklists and pocket guide about biodiversity of the region could help to widen the local knowledge.

We need to develop some more precise measurement tools for measuring diversity and predicting species distribution, for example discriminate analysis and logistic regression.

\section{Acknowledgements:-}

The first author express thanks to the Directorate of Research and Postgraduate Studies, Eritrea Institute of Technology, Eritrea and both the authors express thanks to the Department of Biology for providing laboratory 
facilities for doing tabulation work and also the people of the research site for properly responding and cooperation given to us to obtain the appropriate data for conducting research on this water birds is highly appreciated.

\section{References:-}

1. Abraham, D., Filmon, T. \&Selamawit, T. (2009). An Appraisal of the Current Status and the potential of Surface Water in Upper Anseba Catchment, University of Bern.

2. Adamus, K., Bibby, C., Jones, M. \& Marsden, S. (2001). Expedition Field Techniques: Bird

3. Surveys, Royal Geographical Society, London.

4. Bein, E. (2001).Comment on the paper of Important Bird Areas in Eritrea from EstifanosBein, Ministry of Agriculture, Asmara.

5. Bibby, CJ., Burgess, ND.\& David, H.(1992). Bird Census Techniques, Academic Press, London.

6. Cardinale, BJ., Nelson, k.\& Palmer, MA.(2000). 'Linking species diveristy to the functioning of ecosystems: On the Importance of environmental context',Oikos, Vol. 91, no. 4, pp. 175 - 183.

7. Clergeau, P., Mennechez, G., Sauvage, A.\& Lemoine, A.(2001).Human perception and appreciation of birds: A motivation for wildlife conservation in urban environments of France, Kuwer Academic Publishers, Norwell.

8. Coltherd, JB.(1966). 'The domestic fowl in ancient Egypt', Ibis, Vol. 108, no. 7, pp. 217-223.

9. Czech, B., Krausman, PR..\&Devers, PK.(2000). 'Economic associations anmong causes of species endangerment in the United States', BioScience, Vol. 50, no. 11, pp. $593-601$.

10. David, NH.(n.d). Waterbird conservation for the Americas, Viewed 12 December 2013, <http://www.waterbirdconservation.org/value.html>.

11. Dias, RA.(2006). 'Taxonomic revision identified new tapaculo', World Birdwatch, Vol. 28, no. 8.

12. DoE, (1999).Eritrea Biodiversity Stocktaking Assessment Report, Ministry of Land, Water and Environment, Asmara.

13. Dowsett, RJ.\&Dowsett, LF.(1993).Checklist of the birds of Eritrea, in a contribution to the distribution and taxonomy of Afro-tropical and Malagasy birds, Tauraco Research Report no. 5, Liege, Belgium.

14. Dowsett, RJ. Atkinson, PW.\&Caddick, JA.(2014).Checklist of the birds of Eritrea, Viewed 24 January 2014, <http://www.africanbirdclub.org>.

15. Ehrlich, PR.., Dobkin, DS., Wheye, D.\& Pimm, SL.(1994).The Bird Watcher's Handbook: A Guide to the Natural History of the Birds of Britain and Europe, Oxford University Press, Oxford.

16. Environment Department,(1995).National Environmental Management Plan for Eritrea, Ministry of Land, Water \& Environment, Asmara.

17. Environment Department,(2006).National Environmental management plan for Eritrea, Ministry of Land, Water \& Environment, Asmara.

18. Evans, MI. and Fishpool, LD. (2001).Important Bird Areas in Africa and Associated Islands: Priority Sites for Conservation, Pisces Publications, Cambridge, Birdlife International.

19. Furness, RW.\& Greenwood, JD.(1993).Birds as Monitor of Environmental Change, Chapman and Hall, London.

20. Heywood, VH.(1995).Global Biodiversity Assessment, Cambridge University Press, Cambridge.

21. Hillman, JC.(1992).The Birds of Eritrea: records from the Dahlac Islands, New York Zoological Society/Wildlife Conservation Society, New York.

22. Houlihan, PF.(1986).The birds of Ancient Egypt, John Wiley, Warminster.

23. IUCN,(2006). Birds on the IUCN Red list, Birdlife International, Viewed 04 November 2013,<http://www.birdlife.org>.

24. Jokimaki, J., Clergeau, P.\& Kaisanlahti, JM.(2002). 'winter bird communities in urban habitats: comparative study between central and northern Europe', Biogeography, vol. 29, no. 9, pp. 69 - 79.

25. Karr, JR.(1976). 'Seasonality resource availablity and community diversity in tropical bird communities', America Nature, Vol. 110, no. 2, pp. 937 - 974.

26. Kifle, G.\& Radcliffe, D.(1997).Agro-ecological Zones Map of Eritrea, Ministry of And Water and Environment, Asmara.

27. Krebs, CJ.(2000). Ecological Methodology, $2^{\text {nd }}$ Edn, Addison-Welsey Educational Publisher, USA.

28. Kress, SW.(2000).Birder's Handbook, Dorling Kindersley Publishing, New york.

29. Lawick-Goodall, J.\& Van, H.(1967). 'Use of tools by the Egyptian vulture', Nature, Vol. 212, no. 6, pp. 1468 1469.

30. Lincolin, C., Fredrick, C., Peterson, S.\& Zimmerman, J.(1998).Migration of Birds, United States Fish and Wildlife Society. Washington, D.C. 
31. Liu, J., Daily, GC., Ehrlich, PR.\& Luck, GW.(2003).'Effects of household dynamics on resource consumption and biodiversity', Nature, Vol. 421, no. 3, pp. 530 - 533.

32. Long, JL.(1981).Introduced Birds of the World, Pastone Press, London.

33. Magurran, AA.(1998).Ecological Diversity and Its Measurement, Princeton University Press, Princeton, New Jersey.

34. MoA,(2010).Annual report of the Agricultural Sector of ZobaMaekel, Ministry of Agriculture, Asmara.

35. Negassi, A., Bein, E., Ghebru, K. \&Tengnas, B. (2002). Soil and Water Conservation Manual for Eritrea, RELMA Technical Handbook Series 29, Nairobi.

36. Nemeth, E. \&Bennun, L. (2000). Distribution, habitat selection and behaviour of the East

37. Coast AkalatSheppardiagunningisokokensis in Kenya and Tanzania, Bird Conservation, Nairobi.

38. Pomeroy, D.(1992).Couning Birds: A Guide to Assessing Numbers, Biomass and Diversity of Afro-Tropical Birds, African Wildlife Foundation, Nairobi.

39. Rosenstock, SS., Anderson, DR., Giesen, KM., Leukering, T.\& Carter, MF.(2002). 'Land bird counting techniques: Current Practices and an alternative', Auk, Vol. 119, no. 9, pp. $46-53$.

40. Sinclair, I.\& Ryan, P.(2003).Birds of Africa, Princeton University Press, Princeton, New Jersey.

41. Skole, D.\& Tucker, C.(1993). 'Tropical Deforestation and habitat fragmentation in the Amazon', Science 260, pp. 1905-1910.

42. Smith, KD.(1957). 'An annotated checklist of the birds of Eritrea', Ibis, Vol. 99, no.10, pp.1-26, 307-337.

43. Smith, KD.(1960). 'The passage of Palaearctic migrats through Eritrea', Ibis, Vol. 102, no.6 pp. 536 - 544.

44. State of the Coast Eritrea,(2007).Eritrea's coastal Marine and Islands Biodiversity Conservation project, Ministry of Fisheries, Massawa.

45. Stattersfield, A., Crosby, M., Long, A.\&Wege, D.(1998).Endemic bird areas of the world: priorities for bird conservation, Bird Life International Conservation Series no.7, BirdLife International, Cambridge.

46. Tilman, D.(2000). 'Causes, Consequences and ethics of biodiversity', Nature, Vol. 405, no. 7, pp. 208 - 211.

47. United Nations,(2004).World Urbanization Prospects: The 2004 revision, united Nations, Department of Economic and Social Affairs, Population Division, New York.

48. Vitousek, p., Mooney, H., Lubchenco, J.\& Melillo, J.(1997). 'Human domination of Earth's ecosystems', Science, Vol. 277, no. 10, pp. $494-509$.

49. Vulleumier, F.\& Simberloff, D.(1980). 'Ecology versus history as determinants of patchy and insular distributions in high Andeam birds', Evolutionary Biology, Vol. 12, no. 12, pp. 235 - 379.

50. Wallace, GJ.\& Mahan, HD.(1975).An Introduction to Ornithology, 3rd edn, Macmillan Publishing Co., New York.

51. WCMC,(1992).Global Biodiversity: Status of the Earth's Living Resources, Chapman and Hall, London.

52. Wetland International,(2005).AEWA Conservation guidelines, Wetland International, Wageningen.

53. Wetland International,(2006).Waterbird population Estimates, 4th edn, Wetland International, Wageningen.

54. Wetland International,(2010).Guidance on Waterbird monitoring methodology: field protocol for waterbird counting, 5th edn, Wetland International, Wageningen.

55. Wilson, EO.(1992).The Diversity of Life, Harvard University Press, Cambridge.

56. Woldeamlak, A.\& Haile, BO.(2012). 'Socio economic analysis of food security in Zone Maekel', Hamelmalo Agricultural College, Keren.

57. ZMA,(2009).Annual Work and Budget Plan for 2010, Zone Maekel Administration, Asmara. 